\title{
BMJ Open Domestic violence victimisation and its association with mental distress: a cross- sectional study of the Yangon Region, Myanmar
}

\author{
Win Thuzar Aye (D) , ${ }^{1,2}$ Lars Lien, ${ }^{3}$ Hein Stigum, ${ }^{1}$ Berit Schei, ${ }^{4}$ Johanne Sundby, \\ Espen Bjertness ${ }^{1}$
}

To cite: Aye WT, Lien L, Stigum $\mathrm{H}$, et al. Domestic violence victimisation and its association with mental distress: a cross-sectional study of the Yangon Region, Myanmar. BMJ Open 2020;10:e037936. doi:10.1136/ bmjopen-2020-037936

- Prepublication history for this paper is available online. To view these files, please visit the journal online (http://dx.doi. org/10.1136/bmjopen-2020037936).

Received 21 February 2020 Revised 11 August 2020 Accepted 12 August 2020

Check for updates

(c) Author(s) (or their employer(s)) 2020. Re-use permitted under CC BY-NC. No commercial re-use. See rights and permissions. Published by BMJ.

For numbered affiliations see end of article.

Correspondence to

Dr Win Thuzar Aye;

winthuzaraye@gmail.com

\section{ABSTRACT}

Objectives To estimate the prevalence of domestic violence, with subgroups of physical, sexual and emotional violence, among men and women and to assess the association between any lifetime domestic violence (DV) and mental distress among ever-married men and women. Design We conducted a cross-sectional study from October to November 2016 using a multistage sampling design. DV questionnaire was adopted from the Demographic and Health Survey programme. Mental distress was estimated using the Hopkins Symptom Checklist-10 (HSCL-10). HSCL-score and DV were the outcome and exposure variables, respectively, in multiple linear regression. Prevalence estimates and associations were presented with a $95 \% \mathrm{Cl}$ and the Wald test.

Setting Urban and rural areas of the Yangon region, Myanmar.

Participants Men and women ages 18 to 49 years were included. Institutionalised people, monks, nuns and individuals deemed too ill physically and/or mentally to participate were excluded.

Results A random sample of 2383 people was included in the analyses. Among ever-married participants, lifetime (LT) and past-12-month (12M) prevalence of any domestic violence victimisation was higher in women compared with men: LT women: $61.8 \%$ (95\% Cl: 54.3 to 68.9$)$ versus LT men: $42.4 \%(95 \% \mathrm{Cl}: 37.5$ to 47.5$)$ and $12 \mathrm{M}$ women: $51.2 \%$ (95\% Cl: 44.9 to 57.5 ) versus $12 \mathrm{M}$ men: $37.7 \%$ (95\% Cl: 32.9 to 42.7). Among never-married participants, lifetime physical and sexual violence victimisation rates was higher in men $(34.3 \%$ and $7.9 \%)$ compared with women (19.1\% and 6.4\%). Mental distress was significantly associated with lifetime DV in women who were afraid of their husbands and men who had wives who exhibited controlling behaviours.

Conclusions Domestic violence is prevalent among both men and women and is associated with mental distress. The findings highlight an urgent need to prevent domestic violence in both sexes, including through legal and policy reform and improved mental health services for DV victims.

\section{INTRODUCTION}

Domestic violence (DV) is a significant global public health problem and a violation of
Strengths and limitations of this study

This is the first population-based study conducted in Myanmar estimating the prevalence of domestic violence in men.

- Its high response rate and use of well-established measures of data and an analysis strategy based on a directed acyclic graph strengthen the external and internal validity of the study.

- Its cross-sectional design means that it is not possible to infer a causal relationship between domestic violence and mental distress.

- Recall bias could be present due to the retrospective nature of the questions

- Under-reporting might have resulted due to the sensitive nature of questions about domestic violence.

human rights, with severe consequences for the physical and mental health of affected persons. ${ }^{1}$ The WHO defines domestic violence as 'any behaviour within an intimate relationship that causes physical, psychological or sexual harm, including acts of physical aggression, psychological abuse, forced intercourse and other forms of sexual coercion, and various controlling behaviours'. ${ }^{1}$ The term Domestic Violence (DV) is used for those who have been exposed to physical, psychological or sexual harm by a spouse or among those ever-partnered while living together in an intimate relationship (also labelled as intimate partner violence (IPV)) and for those who are abused by a person in a non-partner relationship. ${ }^{1}$

The Global Burden of Disease Study 2016 estimated that physical violence contributes to 41.2 million years lived with disability (YLDs), while sexual violence contributes 13.7 million YLDs. $^{2}$ Furthermore, a study conducted in Australia found that IPV accounted for $7.9 \%$ of the overall disease burden among 18 to 44 year-old women. ${ }^{3}$ Globally, IPV is 
ubiquitous, with prevalence estimates varying widely within and between communities, countries and regions. A 2013 WHO report on global and regional estimates of violence against women approximates the global lifetime prevalence of physical and/or sexual IPV among all ever-partnered women at $30.0 \%$. The lowest prevalence $(23 \%)$ was found in high-income regions, whereas the highest prevalence was found in low- and middle-income countries (LMIC): Southeast Asia region (37.7\%). ${ }^{4}$ The global lifetime prevalence of non-partnered sexual violence among women was $7.2 \%,{ }^{4}$ with the highest prevalence found in high-income regions $(12.6 \%)$ and the lowest prevalence in LMIC settings of the Southeast Asia region (4.9\%). ${ }^{4}$ Based on the WHO multi-country domestic violence study, the lifetime prevalence rates of physical or sexual IPV in women varied from $15 \%$ (urban Japan) to $62 \%$ (rural Bangladesh), and the past-12-month prevalence ranged between $4 \%$ and $54 \%{ }^{5}$

A report from the Myanmar Demographic Health Survey (MDHS) 2015-2016 estimated that one in five $(21 \%)$ women of reproductive age had experienced some form of IPV in their lifetimes. ${ }^{6}$ More specifically, $15 \%$ reported physical violence, $3 \%$ sexual violence, and $14 \%$ emotional violence. The prevalence of IPV occurring during the past 12 months $(12 \mathrm{M})$ was $15 \%$ for any form of IPV, $10 \%$ for $12 \mathrm{M}$ physical violence, $2 \%$ for $12 \mathrm{M}$ sexual violence, and $10 \%$ for $12 \mathrm{M}$ emotional violence. ${ }^{6}$ Among never-married women, 9 percent had experienced physical violence from any individual, including family members, from the age of 15 years, whereas none of the never-married women reported sexual violence. Although the prevalence data for women are documented in only one recent study, no prevalence data for IPV among men in Myanmar exists.

Although men are also victims of IPV, ${ }^{7-10}$ the vast majority of research globally has focussed on violence perpetrated against women by their male partners. According to a national cross-sectional study in England, $23.8 \%$ of women and $11.5 \%$ of men experienced IPV during their lifetimes. ${ }^{7}$ Based on a 2016 literature review on DV conducted in the USA, more than one in three women $(35.6 \%)$ and one in four men $(28.5 \%)$ age 18 and older reported a lifetime prevalence of physical violence, rape and/or stalking by an intimate partner. ${ }^{11}$

DV affects victims' sexual, reproductive, physical and mental health. DV is associated with a wide range of mental health consequences, such as depression, anxiety, post-traumatic stress disorder, sleep difficulties and suicide attempts. ${ }^{5}$ In a study from Australia, poor mental health was attributed to $73 \%$ of the total IPV disease burden. ${ }^{3} \mathrm{~A}$ systematic review of longitudinal studies reported before 2013 revealed that IPV is a significant contributor to mental health problems, particularly depression, in both sexes. ${ }^{12}$ A more recent prospective cohort study using the Self-Reporting Questionnaire-20 (SRQ-20) reported that women who experienced psychological, physical or sexual violence had three times the increased risk for common mental disorders compared with those with no experiences of violence. ${ }^{13}$
Under the military government from 1962 to 2011, Myanmar society faced a complex combination of vulnerability to natural disasters, violence, war, nutrition insecurity, human trafficking and migration. ${ }^{14}$ The country's sociopolitical difficulties were exacerbated during this period, poverty increased, the educational and health systems became fragmented and the criminal and justice systems became inequitable. ${ }^{14}$ Although domestic violence occurred in the everyday life of communities across the country, it was typically hidden. ${ }^{15}$ Many factors influence domestic violence in Myanmar, for instance, poverty, low-socioeconomic status, alcohol consumption among men, imbalances between power and authority, the influence of traditional and social norms and a lack of legal awareness and human rights. ${ }^{15}{ }^{16}$ In Myanmar society, domestic violence is accepted as a private family matter. Women accept that sex with their husbands is their duty as a wife, and they feel ashamed or stigmatised regarding abuse; thus, domestic violence remains hidden. ${ }^{16}$ Additionally, marital rape is legal; there is no specific law in Myanmar that aims to help prevent marital rape and punish perpetrators. As a consequence, gender inequality and domestic violence persist legally. Myanmar's current rape law is based on a century-old penal code and is not in line with international human rights standards. ${ }^{17}$ Although legislation prohibiting violence against women was drafted in 2013, government approval is still pending. ${ }^{16}$ The aims of the present study among 18 to 49 year-old men and women in the Yangon region of Myanmar are as follows:

1. To estimate the lifetime and past-12-month prevalence of domestic violence (any violence, physical, sexual and emotional) among ever-married men and women;

2. To estimate the lifetime prevalence of domestic violence (physical and sexual) among never-married men and women; and

3. To investigate the association between lifetime domestic violence and mental distress among ever-married men and women.

\section{POPULATION AND METHODS}

\section{Study design and setting}

A household-based cross-sectional study in the northern and southern districts of the Yangon region of Myanmar was conducted among 18 to 49 year-old ever-married and never-married men and women from October to November 2016. The group of 'ever-married' included those who were previously married (ie, currently divorced, separated or widowed). Monks, nuns, soldiers and institutionalised persons were not invited to participate in the study. Exclusion criteria included persons deemed to be too ill physically or mentally to participate. The required sample size was calculated based on the prevalence of DV among married women $(21 \%)$ reported by the Myanmar Demographic and Health Survey (DHS-2016) ${ }^{6}$ and was estimated to be 2400 persons including a $20 \%$ nonresponse rate. 
We adopted a multistage sampling method. First, we purposively selected two districts (north and south) from four districts of the Yangon region. Those were the only districts with both urban and rural populations in the region; the east and west constitute urban areas only. Second, we listed urban wards (an urban subunit of a township) and rural villages from the selected districts. From a total of 125 wards and 235 villages in the northern district and 110 wards and 375 villages in southern district, we randomly selected 8 wards and 8 villages from each of the two districts. Lastly, households were randomly selected using proportional probability sampling from each ward and village based on the proportion of the population in urban and rural areas and the proportion of the population in the northern and southern districts of the Yangon region.

Households were selected from the 16 included wards and 16 included villages based on lists of households obtained from local authorities. We randomly selected 2950 households: 336 and 1034 households from urban wards of the southern and northern districts, respectively, and 686 and 894 corresponding households from rural villages. In each household, one person was asked to list the family members within the age range of 18 to 49 years. From this list, one person was randomly invited to participate in the study using a sealed enveloped method. ${ }^{18}$ One woman and one man were randomly selected from every other household; in 89 households, it was not possible to contact household members. From the remaining 2861 households, 2861 men and women were invited to participate in the study. A total of 130 declined to participate in the study, thus providing a response rate of $92.6 \%$ (2731 of 2950). During data collection, it was not possible to ensure privacy for 152 participants, and therefore, the interview was terminated. An additional 196 participants had incomplete questionnaires and, thus, were excluded from the analyses. The completion rate was $80.8 \%$ (2383 of 2950); the final sample included 2383 participants comprising 1200 men and 1183 women.

\section{Data collection and measurement}

Data were collected by the principal investigator and 12 well-trained field-workers. We applied the standard interviewer guide in the local language as recommended by the WHO. ${ }^{19}$ During the training of research assistants, we emphasised training regarding how to ask sensitive questions, ensure privacy and build trust between interviewer and respondent.

The domestic violence module was based on standard questions adapted from the Myanmar Demographic and Health Survey (DHS). The module had already been translated into the language used most in Myanmar. The WHO DHS domestic violence module is adapted from the Conflict Tactics Scale. ${ }^{20} 21$ Mental distress was measured using the Hopkins Symptom Checklist-10 (HSCL-10), ${ }^{22}$ which was modified from the 25-item version (HSCL25) ${ }^{23}$ The HSCL-10 is internationally accepted and is a widely used screening tool for symptoms of anxiety and depression.

A pilot survey was conducted in a ward not included in the survey area. The interviews were conducted by interviewers of the same gender as the respondents. The objectives of the study and the potential risks and benefits of participating in it were explained to the participants, and written informed consent was given by all participants. They were also informed that their participation was voluntary. In case there was no privacy in the house, we conducted interviews in separate rooms or private areas outside the house. We informed participants that the questions could be sensitive, that their answers would remain completely confidential and that they could refrain from responding from any question while being interviewed. If the interviewer received information about DV, respondents were given information about where to seek health and psychosocial services. ${ }^{24}$ If a respondent did not want to participate or if no one was in the household, this was considered as a non-response. The completeness of each questionnaire was further checked by the principal investigator.

\section{Patient and public involvement}

There was no involvement of patients or the public in designing, recruiting and conducting the study.

\section{Study variables}

Physical violence

If any one of the following conditions was present, it was considered an exposure to physical violence: ${ }^{5}$ being pushed or being shaken; having something thrown at one; being slapped, having an arm twisted or having one's hair pulled; being punched by a partner's fist or hit with something that could hurt; being kicked, dragged or beaten; having a partner choke or burn someone on purpose; being threatened or attacked with a knife, gun or any other weapon.

\section{Sexual violence}

If any one of the following conditions was present, it was considered an exposure to sexual violence: ${ }^{5}$ physically force you to have sexual intercourse with him/her even when you did not want to, physically force you to perform any other sexual acts you did not want to perform or force you with threats or in any other way to perform sexual acts you did not want to perform.

\section{Emotional violence}

If any one of the following conditions was present, it was considered an exposure to emotional violence: ${ }^{5}$ saying or doing something to humiliate you in front of others, threatening to hurt or harm you or someone close to you or insulting you or making you feel bad about yourself.

\section{Lifetime and past-12-month prevalence of domestic violence}

If a respondent gave a positive response to any of the questions on physical, sexual and/or emotional violence, it was considered as exposure to DV. ${ }^{5}$ Lifetime (LT) 
prevalence domestic violence was defined as the proportion of ever-married men or women in intimate relationships who have experienced one or more acts of physical, sexual and/or emotional violence committed by their partners at any point in their life. If such acts occurred in the last 12 months, it was considered as past-12-month prevalence $(12 \mathrm{M})$.

In addition, information was obtained from nevermarried men or women about physical violence they had experienced since the age of 15 years committed by anyone by asking if anyone had hit, slapped, kicked or done something else to hurt them physically. Similarly, information was gathered from never-married men or women about experiences of sexual violence committed by anyone at any time in their life, as a child or as an adult, by asking if they were forced in any way to have sexual intercourse or perform any other sexual acts when they did not want to. We also asked ever-married women about physical violence committed by anyone including their husband while they were pregnant.

\section{Mental distress}

Mental distress was assessed using the HSCL- $10,{ }^{22}$ which comprises 10 items related to symptoms of anxiety and depression during the previous week on a 4-point scale ranging from 1 (not at all) to 4 (extremely). Values above the cut-off $1.85^{22}$ are significantly associated with increased risk of mental distress. The tool has high sensitivity and specificity in identifying distressed and nondistressed individuals among the general population. ${ }^{22}$ In the multivariable analysis, mental distress was used as a continuous variable. ${ }^{22}$

Sociodemographic variables collected in the survey included age, gender, urban-rural location, family structure, the educational difference between partners, income, number of children and age at first marriage. Age (in years) of the respondents was categorised into three age groups, 18 to 29,30 to 39 and 40 to 49 years. Age was also used as a continuous variable in multivariable analysis. The educational difference was the difference in the number of years of education between participants and their partner. If the participant and his/her partner had the same number of years of schooling, the code was 'same education'. If the participant had more years of schooling than his/her partner, the code was 'respondent higher education', and if the participant had fewer years of schooling than his/her partner, the code was 'respondent lower education'. Income was calculated as the total monthly household income divided by the number of residents regardless of age, generating a per capita monthly income. Daily individual income was operationalised as two groups based on the World Bank's cut-off of poverty lines $^{25}$ of 1.90 US $\$ /$ day and 3.10 US $\$ /$ day, that is, low $(<2$ US\$/day) and high ( $\geq 2$ US\$/day).

Behavioural indicators related to DV included the following: partner's controlling behaviour, partner's alcohol consumption, respondent's fear of his/her partner, justifications for wife-beating, witnessing one

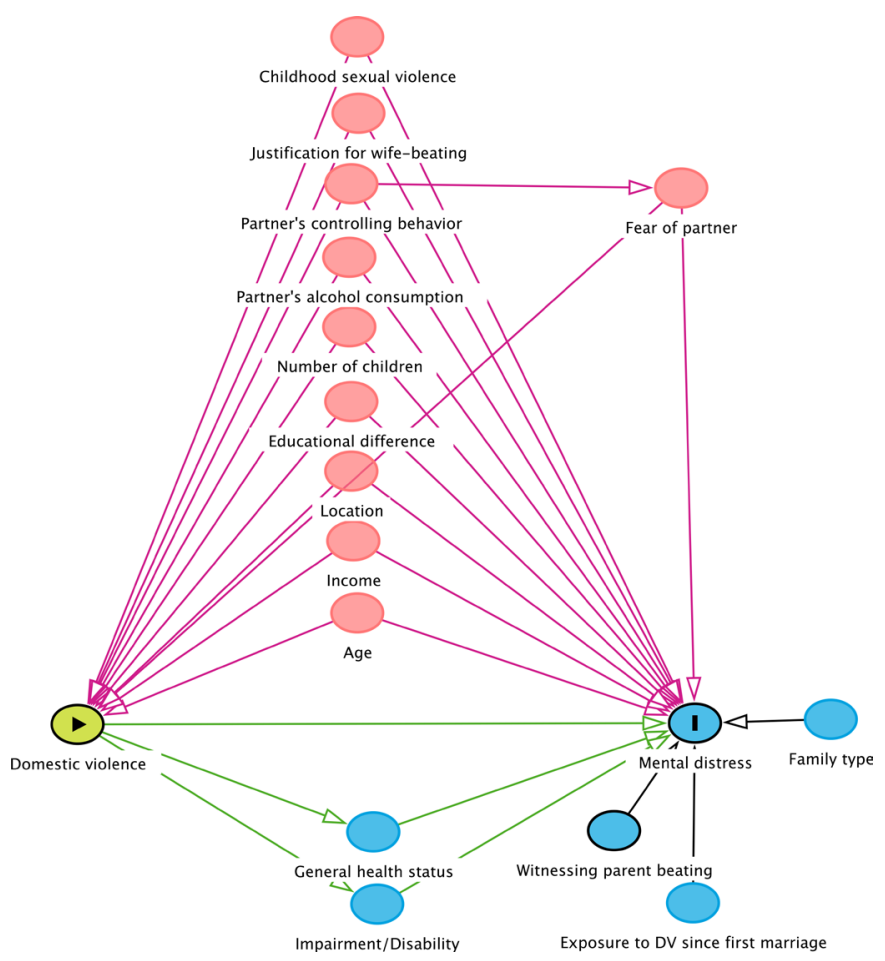

Figure 1 Directed acyclic graph for association between domestic violence and mental distress. DV, domestic violence.

parent beating the other and childhood abuse. Regarding partners' controlling behaviours, the indicators included the following: prevents the respondent from seeing friends, restricts his or her contact with family members, insists on knowing where the respondent is at all times, becomes angry when the respondent talks with other women or men. If the partner committed at least one of the above-mentioned acts, he or she was referred to as a controlling husband or wife. Current health status was dichotomised as 'poor health' (poor, not very good) and 'good health' (good, very good). For the different impairments (mobility, vision, hearing, personal hygiene and memory or concentration), responses were categorised as 'yes' or 'no'.

\section{Statistical methods}

EpiData software V.3.1 was used for double data entry, whereas data management and statistical analysis were performed using Stata/IC V.15.0. We declared complex survey data using 'svyset', and the survey prefix command 'svy' was used in the analysis. For descriptive analyses, we present prevalence estimates with a 95\% CI. Statistical differences between two proportions were computed using a Wald test. The mean was expressed with SD. Multivariable linear regression was used to estimate the association between domestic violence and HSCL-10 score (mental distress), with separate analyses for men and women.

Based on a directed acyclic graph ${ }^{26}$ (figure 1), age, education differences between partners, controlling behaviour, childhood abuse, number of children, 


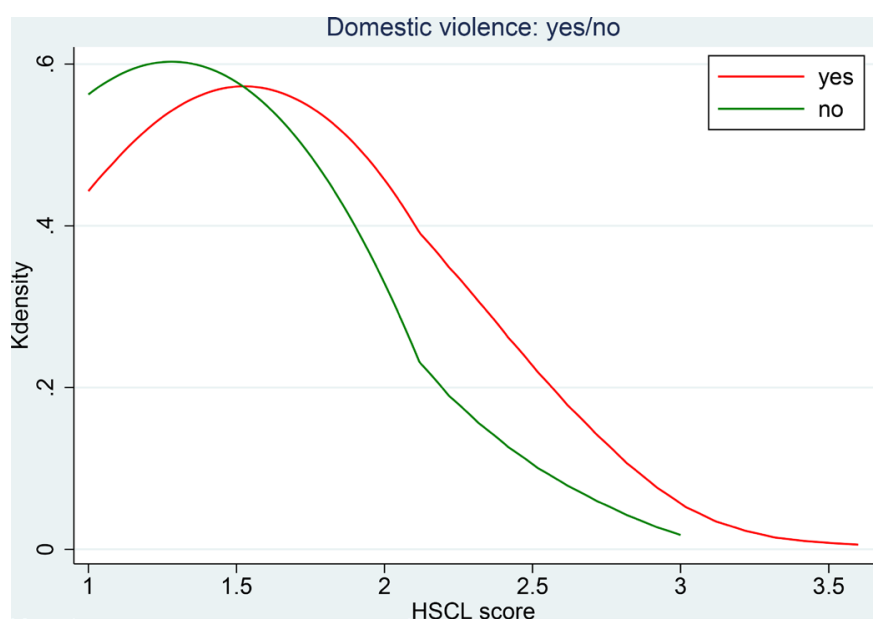

Figure 2 Distribution of HSCL-10 score (mental distress) among exposed and non-exposed to domestic violence in ever-married men and women ages 18 to 49 years in the Yangon Region, Myanmar. HSCL-10,Hopkins SymptomChecklist-10.

income, 'fear of partner', 'justification for wife-beating' and location were defined as confounders in both men and women. An additional confounder for women was 'partner's alcohol consumption'. We stratified on sex and adjusted for the confounders to estimate the total effect of domestic violence on HSCL score (mental distress). We identified an interaction between domestic violence and 'controlling behaviour by partner' in men and an interaction between domestic violence and 'fear of partner' in women. We conducted separate regression analyses for the 'controlling behaviour' group in men and 'fear of partner' group in women.

We checked the distribution of the HSCL-10 scores (mental distress) among the group exposed and unexposed to DV (figure 2), and we found that the distribution was similar but shifted towards higher HSCL scores among those exposed to DV. The assumptions of the linear model (linear effects and constant error variance) were tested by plotting residuals versus predicted values. We looked for observations with high influence by plotting delta-betas versus observation numbers (ID). The only outlier found was not removed from the final analyses as it did not change the estimates when it was removed. All significance tests were two-sided, and $p$ values $<0.05$ were considered to be statistically significant.

\section{RESULTS}

A total of 2383 participants were included in the analyses. Among them, 874 men and 934 women were ever-married, while 326 men and 249 women were nevermarried (figure 3).

\section{Prevalence of DV in men and women}

In both LT (table 1a) and 12M (table 1b) exposures to DV among the married participants, significantly more women than men were exposed to any form of domestic violence: $\mathrm{LT}$ women: $61.8 \%$ (95\% CI: 54.3 to 68.9 ) versus LT men: $42.4 \%$ (95\% CI: 37.5 to 47.5$)$; $\mathrm{p}<0.001$ and $12 \mathrm{M}$ women: $51.2 \%$ (95\% CI: 44.9 to 57.5 ) versus $12 \mathrm{M}$ men: $37.7 \%$ (95\% CI: 32.9 to 42.7 ) ; $\mathrm{p}=0.002$, respectively (table $1 \mathrm{a}$ and $\mathrm{b}$ ). Emotional violence was the most common form, followed by physical and sexual violence in both sexes (table 1a and b). Moreover, the LT prevalence of emotional and physical violence was similar in women $(44.3 \%$ vs $44.2 \%)$. We found that $6.7 \%$ (95\% CI: 4.9 to 9.2 ) of married women had experienced physical violence by anyone including their husband during pregnancy (data not shown). In the never-married participants, the prevalence of both physical and sexual violence was higher in men compared with women (table 1a). Furthermore, unmarried men were more likely to experience sexual violence than married men (7.9\% vs $1.8 \%)$. In married men, the perpetrator was their partner.

\section{Overlap between different forms of DV}

The different forms of domestic violence and their overlapping nature among victims of DV for ever-married and never-married groups are illustrated in figures 4 and 5, respectively. Among the 934 ever-married women, 563 (60.3\%) were exposed to DV (physical, sexual and/or emotional). Among these victims, $118(21 \%)$ were exposed to all three forms of DV (figure 4). Similarly, among the 874 ever-married men, 367 (42\%) were exposed to DV. Among these victims, 10 (2.7\%) were exposed to all three forms of DV (figure 4). Moreover, among the 249 nevermarried women, 46 (18.5\%) were exposed to DV (physical and/or sexual). Among these victims, 3 (7\%) were exposed to both forms of DV (figure 5). Likewise, among the 326 never-married men, 115 (35.3\%) were exposed to DV. Among these victims, 13 (11\%) were exposed to both forms of DV (figure 5).

\section{Bivariate association between DV and selected} sociodemographic, behavioural and health-related factors In bivariate analysis, we found in both sexes that domestic violence was significantly higher among those having

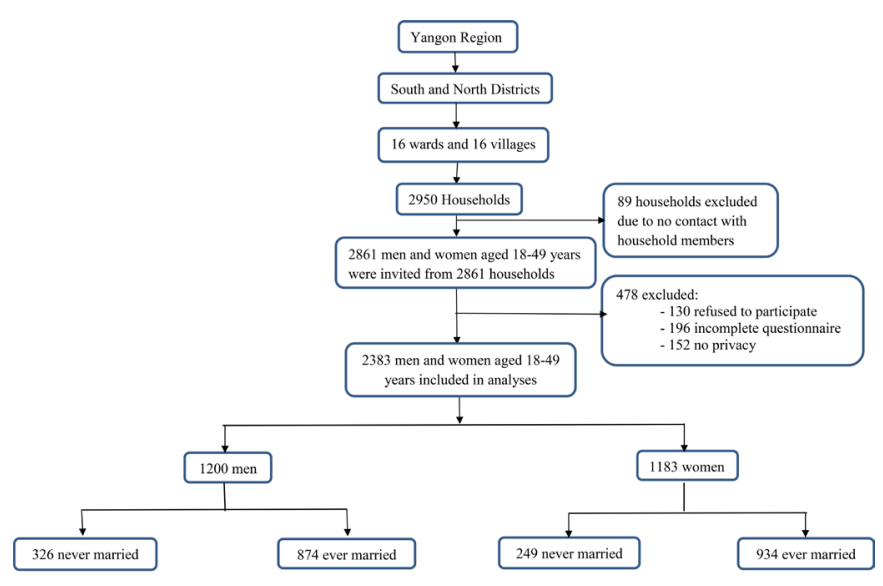

Figure 3 Sampling and analysis flow diagram. 
Table 1a Lifetime prevalence of domestic violence among 18 to 49 year-old men and women in the Yangon region, Myanmar

\begin{tabular}{|c|c|c|c|c|c|c|c|c|c|}
\hline \multirow[b]{3}{*}{ Lifetime violence } & \multicolumn{4}{|c|}{ Men $(n=1200)$} & \multicolumn{5}{|c|}{ Women $(n=1183)$} \\
\hline & \multicolumn{2}{|c|}{ Ever-married $(n=874)$} & \multicolumn{2}{|c|}{ Never-married $(n=326)$} & \multicolumn{3}{|c|}{ Ever-married $(n=934)$} & \multicolumn{2}{|c|}{ Never-married $(n=249)$} \\
\hline & $\mathbf{n}$ & $\begin{array}{l}\text { Prevalence } \\
(95 \% \mathrm{Cl})\end{array}$ & $\mathbf{n}$ & $\begin{array}{l}\text { Prevalence } \\
(95 \% \mathrm{Cl})\end{array}$ & $\mathrm{n}$ & \multicolumn{2}{|c|}{$\begin{array}{l}\text { Prevalence } \\
(95 \% \mathrm{Cl})\end{array}$} & $\mathbf{n}$ & $\begin{array}{l}\text { Prevalence } \\
(95 \% \mathrm{Cl})\end{array}$ \\
\hline Any domestic violence & 367 & $42.4 \%$ (37.5 to 47.5$)$ & - & - & 563 & \multicolumn{2}{|c|}{$61.8 \%$ (54.3 to 68.9$)$} & - & - \\
\hline Emotional violence & 307 & $36.1 \%$ (31.3 to 41.1$)$ & - & - & 407 & \multicolumn{2}{|c|}{$44.3 \%$ (37.9 to 50.9$)$} & - & - \\
\hline Physical violence & 235 & $27.3 \%$ (22.5 to 32.8$)$ & 102 & $34.3 \%$ (25.6 to 44.2$)$ & 390 & \multicolumn{2}{|c|}{$44.2 \%$ (36.1 to 52.7 ) } & 34 & $19.1 \%$ (13.4 to 26.5$)$ \\
\hline \multicolumn{10}{|c|}{$\begin{array}{l}\text { Table } 1 \mathrm{~b} \text { Past-12-month prevalence of domestic violence among } 18 \text { to } 49 \text { year-old ever-married men and women in the } \\
\text { Yangon region, Myanmar }\end{array}$} \\
\hline \multirow{2}{*}{\multicolumn{2}{|c|}{ Past-12-month violence }} & \multicolumn{3}{|l|}{ Men $(n=874)$} & \multicolumn{3}{|c|}{ Women $(n=934)$} & & \\
\hline & & $\mathbf{n}$ & \multicolumn{2}{|c|}{ Prevalence $(95 \% \mathrm{Cl})$} & \multicolumn{2}{|c|}{$\mathbf{n}$} & \multicolumn{3}{|c|}{ Prevalence $(95 \% \mathrm{Cl})$} \\
\hline \multicolumn{2}{|l|}{ Any domestic violence } & 323 & \multicolumn{2}{|c|}{$37.7 \%$ (32.9 to 42.7 ) } & \multicolumn{2}{|c|}{468} & \multicolumn{3}{|c|}{$51.2 \%(44.9$ to 57.5$)$} \\
\hline
\end{tabular}

more than two children as compared with having no children. Participants with the following traits: mental distress, poor self-reported health status and the presence of any impairments were significantly more likely to have experienced domestic violence when compared with those who did not have these traits. Moreover, participants whose partners drank alcohol or were controlling or instilled fear in them also reported a significantly higher prevalence of domestic violence compared with participants whose partner lacked these characteristics (table 2). However, among women, DV was not significantly associated with justification for wife-beating and witnessing a parent being beaten, as opposed to their male counterparts (table 2). Compared with ever-married participants, never-married participants were younger, had higher levels of education and lived with other family members $(\mathrm{p}<0.05$; table 3$)$. No differences were found in regard to urban-rural location, income status, self-perceived health status and mental distress (table 3).

\section{The association between DV and mental distress}

In multivariable linear regression, domestic violence (table 4: Model 2) was significantly associated with mental distress in both men and women after adjusting for confounders (age, income, number of children, location, education difference with partner, controlling behaviour of partner, childhood abuse, fear of partner and justification for wife-beating in men and women). For women, we added their partner's alcohol consumption as a confounder. Among the group that was exposed to domestic violence, the coefficient indicated a 0.18 point (95\% CI: 0.12 to 0.24$)$ increase in the HSCL score for men and a 0.21-point (95\% CI: 0.15 to 0.26 ) increase in the HSCL score for women compared with the group not exposed to domestic violence (ie, the total effect of domestic violence on mental distress). A significant interaction between domestic violence and 'controlling behaviour of partner' was observed in men, whereas domestic violence and 'fear of partner' showed an interaction for women. Men with controlling spouses had a 0.21-point (95\% CI: 0.13 to 0.28 ) significant increase in the HSCL score compared with those without controlling spouses. Those without controlling spouses had only a 0.11 point $(95 \% \mathrm{CI}: 0.03$ to 0.19$)$ significant increase in that score (table 4: Model 4a, b). Women who feared their partners had a 0.39 -point (95\% CI: 0.28 to 0.49 ) significant increase in the HSCL score. Those who were not afraid of their partners had only a 0.18 -point (95\% CI: 0.12 to 0.24 ) significant increase in HSCL score (table 4: Model 4c, d). Only minor deviations from linearity were detected. The regression models showed somewhat increasing error variances. However, using robust variance estimations did not change the results.

\section{DISCUSSION}

This is the first study in Myanmar to explore the association between domestic violence and mental distress, and to estimate the prevalence of DV in men. More than $50 \%$ of the women and $42 \%$ of the men ages 18 to 49 years had experienced some form of lifetime domestic violence perpetrated by their partners. Half of the women and nearly two-fifths of the men had been exposed to domestic violence in the past 12 months. Emotional violence was the most common DV in both lifetime and past 12 months. More specifically, nearly one in two women and one-third of the men reported emotional and physical violence in their lifetime. Moreover, around one-fourth and one-fifth of the women experienced sexual violence in their lifetime and the past 12 months respectively. Among ever-partnered, a higher proportion of women were exposed to all forms of DV compared with ever-partnered men. Furthermore, in the non-partner 
Different forms of Domestic Violence

Number of domestic violence $=563$

Women

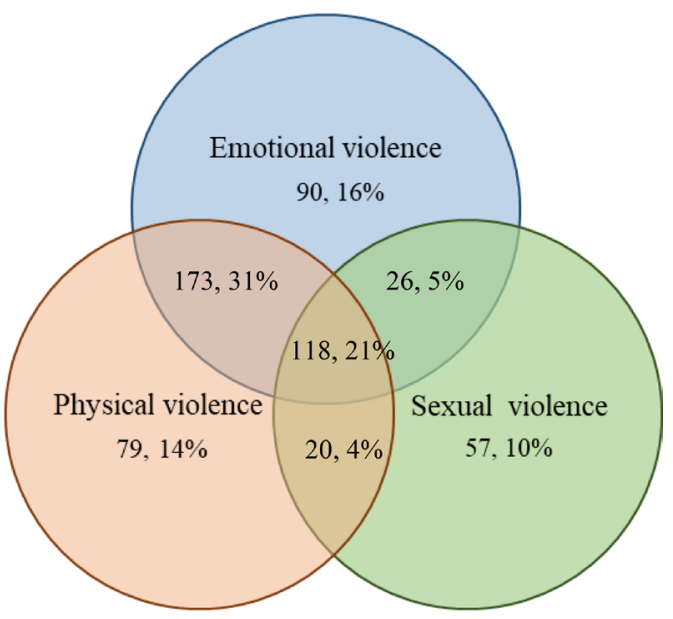

Different forms of Domestic Violence

Number of domestic violence $=367$

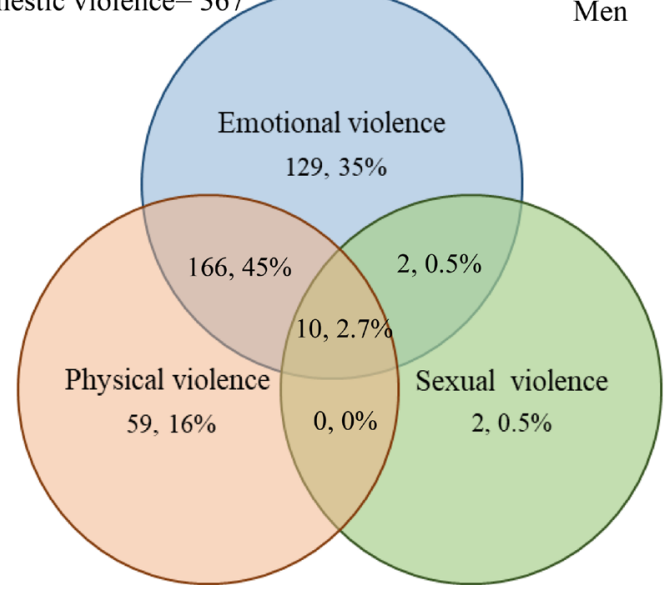

Figure 4 Overlap between lifetime physical, sexual and emotional violence experienced by ever-married women and men ages 18 to 49 years in the Yangon Region, Myanmar ( $\mathrm{n}$, $\%)$.

group, one in five women and one in three men had experienced physical violence by a relative, friend and stranger, from age 15 . The rate of sexual violence did not differ between sexes. A significant association was found between lifetime domestic violence and mental distress among married men with controlling spouses and among women who were afraid of their partners.

\section{Prevalence of any form of $\mathrm{LT}$ and $12 \mathrm{M}$ domestic violence in ever-married women}

In the present study, both the lifetime and the past 12 months prevalence of any form of DV among 18 to 49 year-old married women was substantially higher than the findings reported in the Demography and Health Survey in Nepal 26\% (NDHS 2016) ${ }^{27}$; Ethiopia $34 \%$ (NDHS 2016) $^{28}$ and Myanmar 21\% (MDHS 2015 to 2016). ${ }^{6}$ The methodology and domestic violence questions in our study were similar to the one used in the DHS survey except for some difference in age. We included age groups 18 to 49 years, whereas the DHS studies included ages 15 to 49 . The difference in years might have contributed to slightly higher estimates in the present study. Our prevalence estimates of both the LT and the $12 \mathrm{M}$ were prominently higher than the results from a recent study from Ghana: LT prevalence $(50.9 \%$ ) and $12 \mathrm{M}(34.1 \%) .{ }^{29}$ The questionnaires and age range in this study were similar to our study. In contrast, LT and $12 \mathrm{M}$ prevalence in our study were lower than the rate of any DV in Bangladesh ${ }^{30}$ and Western Ethiopia. ${ }^{31}$ These studies showed that LT and 12M prevalence of any DV were $87 \%$ and $77 \%$, respectively, in Bangladesh and $76.5 \%$ and $72.5 \%$, respectively, in Ethiopia. Moreover, our result of LT prevalence of any form of DV was not much different from the findings in several other countries. For example, a recent study conducted in six countries in the region of sub-Saharan Africa using DHS data estimated that the prevalence of DV in Zambia and Cameron was $53.9 \%$ and $57.6 \%$, respectively. ${ }^{32}$

\section{Prevalence of different types of DV in ever-married women}

The present study demonstrated a higher prevalence of physical, sexual and emotional violence in women than the previous DHS studies. ${ }^{62728}$ However, we found that the LT prevalence of physical violence in this study was significantly lower compared with data from the recent DHS in developing countries: ${ }^{33}$ Bangladesh $(71 \%)$ and Bolivia $(52 \%)$. The LT prevalence of sexual violence in our study was also lower than in Bangladesh $(26 \%){ }^{33}$ The most common form of violence in our study is emotional violence, a finding differs from other demographic and health surveys that found physical violence to be the the
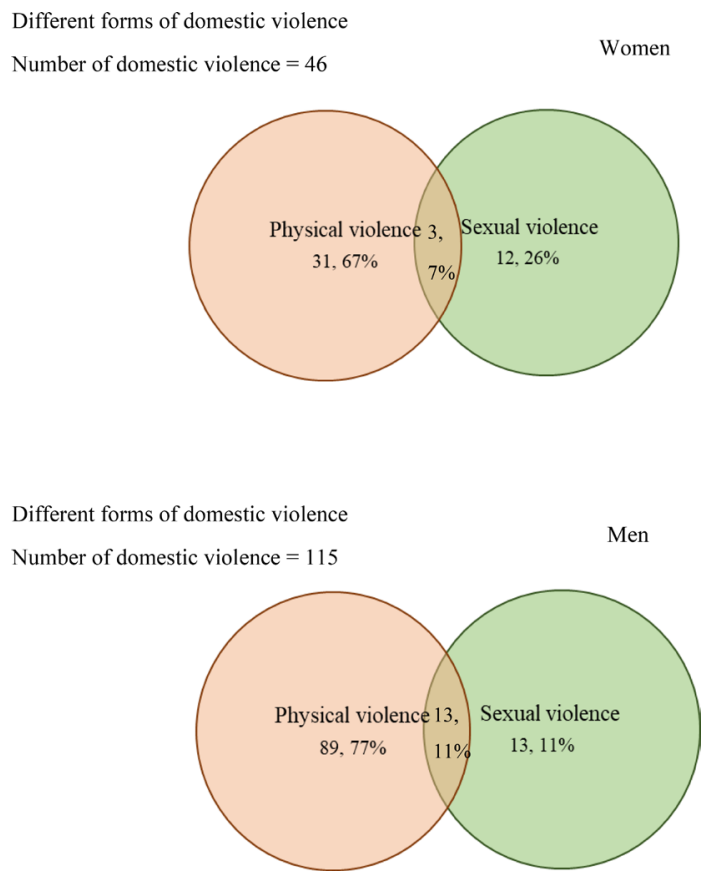

Figure 5 Overlap between physical and sexual violence experienced by never-married women and men ages 18 to 49 years in the Yangon region, Myanmar ( $n, \%)$. 
Table 2 The prevalence of domestic violence by selected sociodemographic, behavioural and health-related factors among 18 to 49 year-old ever-married men and women in the Yangon region, Myanmar

\section{Men ( $\mathbf{n}=\mathbf{8 7 4})$}

Prevalence

N (\%)

\section{Women ( $\mathrm{n}=934)$}

Prevalence

\section{Sociodemographic \\ characteristics}

Age group

$(95 \% \mathrm{Cl})$

P value $\mathrm{N} \quad(\%)$

$(95 \% \mathrm{Cl})$

$P$ value

18-29years
30-39years
40-49years
Location

$230 \quad 38.3$

0.44

0.46

$\begin{array}{ccc}\text { Rural } & 484 & 39.1 \\ \text { Urban } & 390 & 46.7 \\ \text { Education difference* }^{*} & & \end{array}$

Education difference*

$334 \quad 42.6$

(29.2 to 48.2)

$310 \quad 45.9$

(35.9 to 49.5)

(37.2 to 54.7 )

0.44

$\begin{array}{lll}275 & 42.6 & \text { (33.2 to } 52.6) \\ 355 & 64.5 & \text { (55.2 to } 72.8) \\ 386 & 62.7 & \text { (52.8 to } 71.7) \\ \end{array}$

\section{Same education}

$217 \quad 41.8$

39.1

(33.4 to 44.9 )

Respondent higher

$354 \quad 41.7$

(39.0 to 54.5$)$

0.15

education

Respondent lower

$291 \quad 44.0$

$44.0 \quad$ (34.1 to 54.5$)$

(35.1 to 48.7 )

(37.3 to 46.2 )

$466 \quad 54.9$

(47.7 to 61.9$)$

education

tIncome status*

0.40

$$
\begin{aligned}
& \geq 2 \text { US\$/day } \\
& <2 \text { US\$/day }
\end{aligned}
$$

$309 \quad 37.4$

(32.7 to 42.4$)$

$565 \quad 45.5$

(38.8 to 52.3 )

$468 \quad 69.6$

(56.5 to 78.2 )

0.92

Type of family

$$
\text { Nuclear }
$$

Extended

$625 \quad 46.6$

46.6

(41.6 to 51.6$)$

$244 \quad 30.8$

(24.6 to 37.8$)$

$225 \quad 59.2$

(52.5 to 65.5$)$

$288 \quad 58.4$

(48.6 to 67.5 )

Number of children

No children

$162 \quad 30.6$

(19.3 to 44.9$)$

1-2 children

$501 \quad 42.0$

(33.2 to 51.3 )

$\geq 3$ children

$211 \quad 52.6$

(43.0 to 61.9 )

$400 \quad 65.5$

\begin{tabular}{|c|c|c|c|c|c|c|c|c|}
\hline Partner's controlling behaviour & & & & $<0.001$ & & & & $<0.001$ \\
\hline No & 440 & 31.3 & (25.6 to 37.7 ) & & 560 & 51.3 & (42.6 to 59.9$)$ & \\
\hline Yes & 434 & 53.2 & (47.3 to 59.1$)$ & & 374 & 77.5 & (69.2 to 84.1$)$ & \\
\hline Fear of partner & & & & 0.003 & & & & $<0.001$ \\
\hline No & 773 & 38.1 & (32.9 to 43.4 ) & & 696 & 53.6 & (45.1 to 61.9$)$ & \\
\hline Yes & 101 & 80.2 & (66.4 to 89.3 ) & & 238 & 87.1 & (82.6 to 90.6$)$ & \\
\hline Partner's alcohol consumption & & & & 0.002 & & & & $<0.001$ \\
\hline No & 837 & 39.7 & (35.1 to 44.4 ) & & 331 & 47.6 & (38.9 to 56.8 ) & \\
\hline Yes & 37 & 85.3 & (64.4 to 94.9$)$ & & 731 & 69.9 & (62.3 to 76.7$)$ & \\
\hline Justification for wife-beating & & & & 0.004 & & & & 0.58 \\
\hline No & 621 & 38.5 & (33.7 to 43.6 ) & & 560 & 61.0 & (52.5 to 68.9$)$ & \\
\hline Yes & 253 & 52.1 & (44.1 to 59.9 ) & & 439 & 63.1 & (54.6 to 70.8$)$ & \\
\hline Witnessing parent beating & & & & 0.008 & & & & 0.14 \\
\hline No & 685 & 37.8 & (32.6 to 43.2 ) & & 707 & 59.1 & (50.6 to 67.2 ) & \\
\hline Yes & 189 & 58.1 & (47.9 to 67.6 ) & & 227 & 69.2 & (57.8 to 78.7 ) & \\
\hline $\begin{array}{l}\text { Exposure to DV since first } \\
\text { marriage }(m e a n \pm S D)\end{array}$ & 367 & $12.3 \pm 7.9$ & (11.4 to 13.2 ) & $<0.001$ & 558 & $14.4 \pm 8.0$ & $(13.4,15.4)$ & $<0.001$ \\
\hline
\end{tabular}

(54.1 to 75.4$)$

Behavioural characteristics

Continued 
Table 2 Continued

\begin{tabular}{|c|c|c|c|c|c|c|c|c|}
\hline & \multicolumn{4}{|c|}{ Men $(n=874)$} & \multicolumn{4}{|c|}{ Women $(n=934)$} \\
\hline & $\mathbf{N}$ & $\begin{array}{l}\text { Prevalence } \\
\text { (\%) }\end{array}$ & (95\% Cl) & $P$ value & $\mathbf{N}$ & $\begin{array}{l}\text { Prevalence } \\
\text { (\%) }\end{array}$ & (95\% Cl) & $P$ value \\
\hline Childhood sexual violence & & & & 0.65 & & & & 0.92 \\
\hline No & 856 & 42.3 & (37.2 to 47.6 ) & & 838 & 61.8 & (54.0 to 68.9 ) & \\
\hline Yes & 18 & 48.1 & (25.0 to 72.1$)$ & & 96 & 62.4 & (48.1 to 74.9 ) & \\
\hline \multicolumn{9}{|l|}{ Health-related factors } \\
\hline General health status & & & & $<0.001$ & & & & 0.02 \\
\hline \multirow{2}{*}{$\begin{array}{l}\text { Good } \\
\text { Poor }\end{array}$} & 592 & 37.9 & (32.7 to 43.4 ) & & 500 & 56.5 & (48.0 to 64.5 ) & \\
\hline & 275 & 51.6 & (45.4 to 57.8$)$ & & 434 & 68.2 & (59.2 to 76.0$)$ & \\
\hline flmpairment & & & & 0.001 & & & & 0.03 \\
\hline No & 478 & 35.6 & (30.3 to 41.3 ) & & 392 & 57.1 & (48.0 to 65.8 ) & \\
\hline Yes & 396 & 50.9 & (44.2 to 57.5$)$ & & 542 & 65.3 & (57.2 to 71.9 ) & \\
\hline$\S$ Mental distress & & & & 0.009 & & & & $<0.001$ \\
\hline No & 723 & 39.1 & (34.2 to 44.3 ) & & 720 & 56.3 & (49.3 to 63.0$)$ & \\
\hline Yes & 142 & 58.6 & (47.9 to 68.6 ) & & 214 & 83.5 & (74.5 to 89.7$)$ & \\
\hline Age at first marriage* & & & & 0.14 & & & & $<0.001$ \\
\hline Younger than 18 years & 85 & 51.0 & (39.9 to 62.1 ) & & 269 & 74.1 & (65.1 to 81.4$)$ & \\
\hline 18 years or older & 787 & 41.6 & (36.8 to 46.8 ) & & 655 & 56.6 & (48.4 to 64.5$)$ & \\
\hline
\end{tabular}

*Information missing for some respondents because they 'don't know'.

†Exchange rate: US\$1=1363 Myanmar Kyats as of 4 November 2018.

†Impairment related to mobility/hearing/vision/personal hygiene/memory, concentration-a positive response for any symptom is noted as (Y).

$\S$ Mental distress ( $\geq 1.85 \mathrm{HSCL}-10$ score).

DV, domestic violence; HSCL-10, Hopkins Symptom Checklist-10.

most common form. ${ }^{62728}$ Similar to our study results, data from a previous survey in Myanmar using different questionnaires, showed that there was a high prevalence of emotional violence and that the prevalence of physical violence was low. The previous survey was a communitybased multistage sampling survey from Mandalay township (the second largest city of Myanmar). It estimated that $69 \%$ of women aged 18 to 59 years experienced emotional violence from their husband in the past 12 months, while $27 \%$ reported physical violence. ${ }^{34}$

\section{The overlapping nature of DV in ever-married women and men} Studies on the overlaps between different types of DV are limited. The overlap of all three forms of DV among married women in our study is in accordance with the previous population-based study in Sweden $(22 \%),{ }^{35}$ which applied similar instrument with the present study. On the contrary, our overlap of all three types of violence is higher than the reported in Nepal $(12.4 \%)^{36}$ but lower than a Western Ethiopian study $(56.9 \%) .{ }^{31}$ One possible explanation might be sociocultural difference and traditional norms. Women in the Myanmar society accept domestic violence as a private matter and are shameful to disclose domestic violence to other persons. ${ }^{16}$ Additionally, women feel they have responsibility to fulfil their husband's desire, thus they do not consider marital rape as a violence. ${ }^{16}$ A 2014 qualitative study of violence against women in Myanmar reported that most women experienced more than one type of violence. ${ }^{16}$ Compared with the Swedish population-based study, ${ }^{35}$ the concurrent exposure of all forms of violence reported by men in our study is low.

\section{Prevalence of DV in ever-married men}

Few studies have investigated DV among men. We report a higher lifetime prevalence of any domestic violence, as compared with population-based national, cross-sectional surveys in England $(11.5 \%)^{7}$ and Sweden $(15.3 \%),{ }^{35}$ and the National Violence Against Women Survey (NVAWS) in the USA $(23.3 \%) .{ }^{37}$ While comparing specific types of violence (physical, emotional and sexual), the current study reports a higher prevalence of emotional and physical violence than these studies from England, Sweden, and the USA. Moreover, our study's report of sexual violence was higher than these studies from England and USA except Sweden. A possible explanation is that there might be bi-directional violence between the partners, with both partners perpetrating acts of physical violence. Domestic violence is most commonly reciprocal, ${ }^{38}$ and some women perpetrated the violence to defend themselves verbally and physically. ${ }^{16}$ Whitaker et al reported that women abuse men at similar rates as men abuse 
Table 3 Sociodemographic and health-related factors by never-married and ever-married men and women ages 18 to 49 years in the Yangon region, Myanmar

\begin{tabular}{|c|c|c|c|c|c|c|c|}
\hline & \multicolumn{3}{|c|}{ Never-married $(n=575)$} & \multicolumn{3}{|c|}{ Ever-married $(n=1808)$} & \multirow[b]{2}{*}{$P$ value } \\
\hline & $\mathbf{N}$ & $\begin{array}{l}\text { Prevalence } \\
\text { (\%) }\end{array}$ & $(95 \% \mathrm{Cl})$ & $\mathbf{N}$ & $\begin{array}{l}\text { Prevalence } \\
(\%)\end{array}$ & $(95 \% \mathrm{Cl})$ & \\
\hline \multicolumn{8}{|l|}{$\begin{array}{l}\text { Sociodemographic } \\
\text { characteristics }\end{array}$} \\
\hline \multicolumn{8}{|l|}{ Age group } \\
\hline 18-29years & 393 & 45.0 & (39.3 to 50.9 ) & 505 & 54.9 & (49.1 to 60.7 ) & $<0.001$ \\
\hline 30-39years & 111 & 14.1 & (11.3 to 17.4 ) & 689 & 85.9 & (82.7 to 88.7 ) & \\
\hline 40-49years & 71 & 9.1 & (6.8 to 12.1$)$ & 614 & 90.9 & (87.9 to 93.2 ) & \\
\hline Location & & & & & & & 0.56 \\
\hline Rural & 292 & 26.2 & (21.2 to 31.9 ) & 950 & 73.8 & (68.1 to 78.8 ) & \\
\hline Urban & 283 & 24.1 & (20.1 to 28.7 ) & 858 & 75.9 & (71.3 to 79.9 ) & \\
\hline Education & & & & & & & 0.001 \\
\hline$\leq 5$ years & 124 & 13.4 & (11.4 to 15.8$)$ & 750 & 86.6 & (84.2 to 88.6 ) & \\
\hline $6-11$ years & 293 & 29.1 & (24.5 to 34.3 ) & 835 & 70.9 & (65.7 to 75.6$)$ & \\
\hline$>11$ years & 158 & 41.8 & (35.4 to 48.4 ) & 223 & 58.2 & (51.6 to 64.6 ) & \\
\hline${ }^{*}$ Income status $\dagger$ & & & & & & & 0.23 \\
\hline$\geq 2$ US\$/day & 246 & 26.8 & (23.4 to 30.5 ) & 741 & 73.2 & (69.5 to 76.6 ) & \\
\hline$<2$ US\$/day & 324 & 23.7 & (19.1 to 29.1) & 1067 & 76.3 & (70.9 to 80.9 ) & \\
\hline Type of family & & & & & & & $<0.001$ \\
\hline Nuclear & 68 & 4.7 & (3.1 to 7.2 ) & 1353 & 95.3 & (92.7 to 96.9 ) & \\
\hline Extended & 507 & 56.4 & (50.4 to 62.3 ) & 455 & 43.6 & (37.7 to 49.7 ) & \\
\hline \multicolumn{8}{|l|}{ Health-related factors } \\
\hline General health status & & & & & & & 0.10 \\
\hline Good & 391 & 27.0 & (22.7 to 31.9 ) & 1099 & 72.9 & (68.1 to 77.3 ) & \\
\hline Poor & 184 & 22.4 & (18.6 to 26.7 ) & 709 & 77.6 & (73.3 to 81.4 ) & \\
\hline †Impairment & & & & & & & 0.002 \\
\hline No & 334 & 28.7 & (25.4 to 32.1 ) & 870 & 71.4 & (67.9 to 74.6 ) & \\
\hline Yes & 241 & 21.7 & (17.3 to 26.9 ) & 938 & 78.3 & (73.0 to 82.7 ) & \\
\hline$\S M$ Mental distress & & & & & & & 0.36 \\
\hline No & 492 & 25.9 & (22.9 to 29.1 ) & 1452 & 74.1 & (70.9 to 77.1$)$ & \\
\hline Yes & 83 & 22.4 & (14.9 to 32.4 ) & 356 & 77.6 & (67.7 to 85.1$)$ & \\
\hline
\end{tabular}

*Exchange rate: US\$1=1363 Myanmar Kyats as of 4 November 2018.

†Information missing for some respondents because they 'don't know'.

†lmpairment related to mobility/hearing/vision/personal hygiene/memory, concentration-a positive response for any symptom is noted as (Y).

§Mental distress ( $\geq 1.85 \mathrm{HSCL}$ score).

HSCL, Hopkins Symptom Checklist.

women. ${ }^{39}$ A review of 62 empirical studies on female perpetration of violence in intimate relationships between 1996 and $2006^{39}$ indicated that emotional violence is the most common violence perpetrated by women, followed by physical and sexual violence which is in line with our study results.

\section{Prevalence of DV in never-married women and men}

Data for comparing the prevalence of physical and sexual violence in non-partnered (single) men are scarce. In non-partnered women, we found that, in our study, the prevalence of non-partner physical and sexual violence from the age of 15 years perpetrated by anyone (friend, relative, stranger) was higher than the prevalence found in the DHS studies in Myanmar, Nepal and Ethiopia. ${ }^{627} 28$ Prevalence of physical and sexual violence in these countries was $9 \%$ and $0 \%$ in Myanmar, $6 \%$ and $2 \%$ in Nepal, and $7 \%$ and $2 \%$ in Ethiopia, respectively. Moreover, the nonpartner sexual violence rate in our study was higher than 
Table 4 Association between domestic violence and mental distress (HSCL-10) among 18 to 49 year-old ever-married men and women citizens in the Yangon region, Myanmar

\begin{tabular}{|c|c|c|c|c|c|c|c|}
\hline \multirow[b]{2}{*}{ Model } & \multirow[b]{2}{*}{ Description } & \multirow{2}{*}{$\begin{array}{l}\text { Men } \\
\text { Coefficient* }^{\star}\end{array}$} & \multirow[b]{2}{*}{$95 \% \mathrm{Cl}$} & \multirow[b]{2}{*}{$P$ value } & \multirow{2}{*}{$\begin{array}{l}\text { Women } \\
\text { Coefficient* }\end{array}$} & \multirow[b]{2}{*}{$95 \% \mathrm{Cl}$} & \multirow[b]{2}{*}{$P$ value } \\
\hline & & & & & & & \\
\hline 1 & Crude & 0.23 & 0.17 to 0.29 & 0.0001 & 0.27 & 0.23 to 0.32 & 0.0001 \\
\hline $2 \dagger$ & Adjusted & 0.18 & 0.12 to 0.24 & 0.0001 & 0.21 & 0.15 to 0.26 & 0.0001 \\
\hline $3 a$ & Interaction, controlling behaviour (yes) & 0.21 & 0.13 to 0.28 & 0.0001 & - & - & - \\
\hline $3 b$ & Interaction, controlling behaviour (no) & 0.11 & 0.03 to 0.19 & 0.005 & - & - & - \\
\hline $3 c$ & Interaction, fear of partner (yes) & - & - & - & 0.39 & 0.28 to 0.49 & 0.0001 \\
\hline $3 d$ & Interaction, fear of partner (no) & - & - & - & 0.18 & 0.12 to 0.24 & 0.0001 \\
\hline
\end{tabular}

Confounders adjusted in women: age, education difference with partner, controlling behaviour, childhood abuse, number of children, income, justification for wife-beating, fear of partner, location and partner's alcohol consumption. ${ }^{*}$ Coefficients with $95 \% \mathrm{Cl}$ from linear regression.

†Confounders adjusted in men: age, education difference with partner, controlling behaviour, childhood abuse, number of children, income, justification for wife-beating, fear of partner and location. HSCL-10, Hopkins Symptom Checklist-10.

in the Southeast Asia region and lower than in African and American regions. ${ }^{4}$ The variation in prevalence rates among different countries may be attributed to methodological complexities and sociocultural differences among women and men in these countries. Moreover, religious practices and economic and political conditions might create conditions that either increase or decrease the rate of domestic violence. ${ }^{50} \mathrm{~A}$ possible explanation for the higher prevalence rate of domestic violence in the present study may be our ability to build trust between the respondent and the interviewer. In particular, the interviewers were trained to create a conducive environment that facilitated the disclosure of domestic violence. Moreover, the majority of participants in this study agreed with statements in the questionnaires that domestic violence is an important issue for community safety. In comparison to Myanmar DHS (2015 to 2016), even though the response rate was similar, the prevalence of any form and different types of DV was much higher in our study. This difference may be attributed to the trust-building mentioned above and to the language barrier between interviewers and respondents because DHS sampled the entire country, which included more than 130 minority groups with even more different languages. The DHS survey questions were translated only into the Burmese language, excluding the various languages spoken by minority groups. Thus, it is possible that the language used in the Myanmar DHS survey was difficult to understand for some minority ethnic populations and, as such, negatively impacted the results. In the present study, we collected data in the Yangon region where all the respondents understood Burmese language.

\section{Difference in the prevalence rate by sex}

From a gender perspective, we report that the prevalence of DV is higher among women than men, a finding that has been reported in studies from England, the USA and Sweden. ${ }^{732} 35$ In Myanmar's culture, men are considered as the head of households and the main breadwinners who make important decisions in the family. ${ }^{16}$ Moreover, factors such as cultural sensitivity, gender inequality, the subordination of women in the community setting and low levels of awareness of domestic violence increase women's vulnerability to violence. ${ }^{16}$ In the society of Myanmar, domestic violence has been normalised to some women, especially those from lower socioeconomic groups, who accept such violence as a part of their lives. ${ }^{16}$

\section{Association between DV and mental health}

Our findings of an association between DV and mental health support those of the WHO multi-country study, ${ }^{541}$ which reported that DV is associated with both poor physical and mental health. ${ }^{51}$ Similar findings have been reported elsewhere. ${ }^{13}{ }^{42-45}$ A recent prospective cohort study in Brazil ${ }^{13}$ enumerated that women who experienced any form of DV during a 7-year period had a significantly increased risk of common mental disorders (depression and anxiety) compared with women who did not. Our study aligns with the Brazilian cohort study. Nearly all studies that examined the effect of IPV on mental health use the past-12-month IPV as exposure. An exception is the US NVAWS, ${ }^{37}$ which examined the effect of lifetime IPV on mental health in both sexes. The survey, using the Beck Depression Inventory questionnaire, indicates that lifetime IPV (physical and emotional) are significantly associated with mental health problems (depressive symptoms), a result that is consistent with the findings of the present study, in which we report that a partner's controlling behaviour and ability to instil fear in the spouse make the association between DV and mental distress stronger. Several recent studies ${ }^{44} 45$ have revealed that women who mentioned controlling behaviours by their partner are more likely to be exposed to DV and to suffer from mental health problems than women who do not have partners with controlling behaviours. Although we adjusted for confounding variables in the association between DV and mental distress, residual confounding such as separate income of respondents and partners, 
their parental backgrounds and parental roles may still exist. Moreover, a longitudinal study among Korean women reported that there was a reciprocal relationship between IPV and depression. ${ }^{46}$

The main strength of this study is the exploration of different forms of domestic violence in both married and unmarried men and women. The high response rates minimise selection bias. We used internationally standardised questionnaires ${ }^{6}$ that were already translated into the Burmese language and back-translated to English, reducing potential information bias. A limitation of the study is a potential underestimation of the prevalence of domestic violence due to the sensitivity of the questions, as discussed in previous international studies. ${ }^{9} 1347$ Such information bias may have arisen because domestic violence victims are sometimes reluctant to recall traumatic events or to reveal their partner's violent behaviour. ${ }^{48}$ Violence might also be under-reported due to feelings of guilt, shame or fear. However, special training for the interviewers, conducting interviews with same-sex respondents, and building respondents' trust might have reduced the under-reporting and social desirability bias. Another limitation is that the HSCL-10 was not validated in this study population; however, it has previously been validated in the general population in Pakistan, ${ }^{49}$ Norway $^{22}$ and in an ethnic minority population. ${ }^{50}$ In addition, the standard English version of the HSCL-10 was translated into the Burmese language by a psychiatrist and back-translated, and a pilot study was conducted, resulting in minor corrections. Nevertheless, we cannot rule out whether the symptoms of mental distress in the present study are overestimated or underestimated. Thus, the results should be interpreted with caution. Due to the exclusion of members of military, institutionalised people, monks and nuns, we may also have introduced selection bias. However, it is not possible to elucidate the direction of this potential bias. Another limitation is that we were unable to properly establish the direction of effect between lifetime domestic violence and mental distress due to the cross-sectional study design.

\section{CONCLUSIONS}

We report a high prevalence of various forms of domestic violence among 18 to 49 year-old married women and men. Furthermore, we report an association between lifetime exposure to domestic violence and mental distress. Despite government sectors and non-governmental organisations working together to eliminate gender inequality, the prevalence of domestic violence remains higher among married women than married men. Thus, it is recommended that policymakers emphasise culturally appropriate outreach programmes to increase the awareness of domestic violence and to provide guidance on how to access mental health services for domestic violence victims. The health system needs to ensure good coordination systems and to create a referral network for domestic violence victims. Additionally, the health professional who treats domestic violence victims should screen for symptoms of mental health problems. In this study, we examined the association between all types of domestic violence and mental distress. There is a need for further research on how each type of domestic violence impacts mental health. Moreover, longitudinal studies are needed in order to identify cause and effect relationships between domestic violence and mental distress.

\section{Author affiliations}

${ }^{1}$ Department of Community Medicine and Global Health, Institute of Health and Society, University of Oslo Faculty of Medicine, Oslo, Norway

${ }^{2}$ Department of Preventive and Social Medicine, University of Medicine (2), Yangon, Myanmar

${ }^{3}$ National Norwegian advisory board for concurrent addiction and mental health problems, Innlandet Hospital Trust, Brumunddal and Faculty of Social and Health Sciences, Inland Norway University of Applied Science, Elverum, Oslo, Norway ${ }^{4}$ Department of Public Health and Nursing, Faculty of Medicine and Health Sciences, Norwegian University of Science and Technology, Trondheim, Norway

Acknowledgements The authors would like to thank all the respondents and local authorities and those from the Yangon Regional Health Department, Department of Public Health, Myanmar, who assisted in the study. We also wish to extend our gratitude and appreciation to the MY-NORTH project funded by Norad through the NORHED programme.

Contributors WTZA contributed to the design of the study, the data collection, the data analysis and the interpretation and preparation of the draft manuscript. LL participated in the design of the study and commented on the draft. HS conducted data analysis and interpretation of the data. BS and JS contributed to the interpretation of the data and provided intellectual input on the draft. EB was the key contributor for the conception and design of the study and interpretation of the data and provided intellectual input on the draft. All authors read and approved the final content of the manuscript.

Funding The research was funded by the Norwegian programme (Norad/NORHED) for Capacity Development in Higher Education and Research for Development through the project entitled Health and Sustainable Development in Myanmar - Competence building in public health and medical research and education, MY-NORTH. Project: MMY-13/0049 (MY-NORTH-1300650).

Competing interests None declared.

Patient consent for publication Obtained.

Ethics approval In Myanmar, the study was approved by the University of Public Health and Ministry of Health and Sports. In Norway, approval was granted by the Regional Committees for Medical and Health Research Ethics (REK). All participants signed an informed consent form. To ensure privacy and confidentiality, respondents' names, addresses and personal ID were removed from questionnaires and data files.

Provenance and peer review Not commissioned; externally peer reviewed.

Data availability statement Data are available upon reasonable request. Not available for additional data.

Open access This is an open access article distributed in accordance with the Creative Commons Attribution Non Commercial (CC BY-NC 4.0) license, which permits others to distribute, remix, adapt, build upon this work non-commercially, and license their derivative works on different terms, provided the original work is properly cited, appropriate credit is given, any changes made indicated, and the use is non-commercial. See: http://creativecommons.org/licenses/by-nc/4.0/.

\section{ORCID iD}

Win Thuzar Aye http://orcid.org/0000-0002-6087-5277

\section{REFERENCES}

1 World Health Organization. Responding to intimate partner violence and sexual violence against women: WHO clinical and policy guidelines. Geneva World Health Organization; 2013a. http://apps. who.int/rhl/guidelines/9789241548595/en 
2 GBD 2016 Disease and Injury Incidence and Prevalence Collaborators. Global, regional, and national incidence, prevalence, and years lived with disability for 328 diseases and injuries for 195 countries, 1990-2016: a systematic analysis for the global burden of disease study 2016. Lancet 2017;390:1211-59.

3 Vos T, Astbury J, Piers LS, et al. Measuring the impact of intimate partner violence on the health of women in Victoria, Australia. Bull World Health Organ 2006;84:739-44.

4 WHO. Global and regional estimate of violence against women: prevalence and health effects of intimate partner violence and nonpartner violence. Available: https://www.who.int/reproductivehealth/ publications/violence/24159358X/en

5 Garcia-Moreno C, Jansen H, Heise L. WHO multi-country study on women's health and domestic violence, against women. Initial results on prevalence, health outcomes and women's response. Geneva World Health Organization; 2005.

6 Ministry of Health and Sports - MoHS/Myanmar and ICF. Myanmar demographic and health survey 2015-16, 2017. Available: https:// dhsprogram.com/pubs/pdf/FR324/FR324.pdf

7 Khalifeh H, Hargreaves J, Howard LM, et al. Intimate partner violence and socioeconomic deprivation in England: findings from a national cross-sectional survey. Am J Public Health 2013;103:462-72.

8 Barros CRDS, Schraiber LB. Intimate partner violence reported by female and male users of healthcare units. Rev Saude Publica 2017;51:7.

9 Carmo R, Grams A, Magalhães T, et al. Men as victims of intimate partner violence. J Forensic Leg Med 2011;18:355-9.

10 Breiding MJ, Ziembroski JS, Black MC, et al. Prevalence of rural intimate partner violence in 16 US states, 2005. J Rural Health 2009;25:240-6.

11 Chibber K, Cantor J, Greenberg E. Domestic violence literature review: analysis report. California JSI Research \& Training Institute Inc; 2016

12 Devries KM, Mak JY, Bacchus LJ, et al. Intimate partner violence and incident depressive symptoms and suicide attempts: a systematic review of longitudinal studies. PLoS Med 2013;10:e1001439.

13 Mendonça MFSde, Ludermir AB. Intimate partner violence and incidence of common mental disorder. Rev Saude Publica 2017;51:32-3.

14 Stokke K, Vakulchuk R, Øverland I. Myanmar: a political economy analysis. Oslo: Norwegian Institute of International Affairs, 2018.

15 UNFPA Myanmar. A silent emergency: violence against women and girls, 2016. Available: https://myanmar.unfpa.org/en/news/silentemergency-violence-against-women-and-girls

16 The Gender Equality Network. Behind the silence: violence against women and their resilience, Myanmar. Yangon, Myanmar, 2015. Available: https://www.burmalibrary.org/docs21/GEN-2015-02Behind_the_Silence-en-red.pdf

17 Burma Penal code No.375 (1860). Available: http://mm.myanmars. net/laws/index.php/2012-01-30-06-42-02/759-1860-45the-penalcode-chapter-16

18 Torgerson DJ, Roberts C. Randomisation methods: concealment BMJ 1999;319:375-6.

19 Jansen Het al. Interviewer Training in the WHO Multi-Country Study on Women's Health and Domestic Violence 2004.

20 Straus MA. Measuring intrafamily conflict and violence: the conflict tactics (CT) scales. J Marriage Fam 1979;41:75-88.

21 Straus MA. Measuring intrafamily conflict and violence: The conflict tactic (CT) scales. In: Straus MA, Gelles RJ, eds. Physical violence in American families: risk factors and adaptations to violence in 8,145 families. New Brunswick: Transaction Publishers, 1990: 29-47.

22 Strand $\mathrm{BH}$, Dalgard OS, Tambs K, et al. Measuring the mental health status of the Norwegian population: a comparison of the instruments SCL-25, SCL-10, SCL-5 and MHI-5 (SF-36). Nord J Psychiatry 2003;57:113-8.

23 Derogatis LR, Lipman RS, Rickels K, et al. The Hopkins symptom checklist (HSCL): a self-report symptom inventory. Behav Sci 1974;19:1-15.

24 Hotline aims to help domestic abuse victims. Available: https://www. mmtimes.com/national-news/23270-hotline-aims-to-help-domesticabuse-victims

25 PovcalNet. The world bank an online analysis tool for global poverty monitoring, 2016. Available: http://iresearch.worldbank.org/ PovcalNet/povOnDemand.aspx

26 Textor J, van der Zander B, Gilthorpe MS, et al. Robust causal inference using directed acyclic graphs: the R package 'dagitty'. Int J Epidemiol 2016;45:1887-94.

27 Ministry of Health, New ERA,ICF. Nepal demographic and health survey 2016. Kathmandu, Nepal Ministry of Health, Nepal; 2016.
28 Central Statistical Agency (CSA) [Ethiopia] and ICF. Ethiopia demographic and health survey 2016 Addis Ababa, Ethiopia, and Rockville, Maryland, US: CSA and ICF; 2016

29 Ogum Alangea D, Addo-Lartey AA, Sikweyiya Y, et al. Prevalence and risk factors of intimate partner violence among women in four districts of the central region of Ghana: baseline findings from a cluster randomised controlled trial. PLoS One 2018;13:e0200874.

30 Bangladesh Bureau of Statistics. Report on violence against women (VWA) survey 2011; 2013.

31 Abeya SG, Afework MF, Yalew AW. Intimate partner violence against women in Western Ethiopia: prevalence, patterns, and associated factors. BMC Public Health 2011;11:913.

32 Bamiwuye SO, Odimegwu C. Spousal violence in sub-Saharan Africa: does household poverty-wealth matter? Reprod Health 2014;11:45.

33 Hindin MJ, Kishor S, Ansara DL. Intimate partner violence among couples in 10 DHS countries: predictors and health outcomes. DHS analytical studies No. 18. Calverton, Maryland, US Macro International Inc; 2008.

34 Kyu N, Kanai A. Prevalence, antecedent causes and consequences of domestic violence in Myanmar. Asian J Soc Psychol 2005;8:244-71.

35 Nybergh L, Taft C, Enander V, et al. Self-Reported exposure to intimate partner violence among women and men in Sweden: results from a population-based survey. BMC Public Health 2013;13:845.

36 Sapkota D, Bhattarai S, Baral D, et al. Domestic violence and its associated factors among married women of a village development Committee of rural Nepal. BMC Res Notes 2016;9:178.

37 Coker AL, Davis KE, Arias I, et al. Physical and mental health effects of intimate partner violence for men and women. Am J Prev Med 2002;23:260-8.

38 Williams JR, Ghandour RM, Kub JE. Female perpetration of violence in heterosexual intimate relationships: adolescence through adulthood. Trauma Violence Abuse 2008;9:227-49.

39 Whitaker DJ, Haileyesus T, Swahn M, et al. Differences in frequency of violence and reported injury between relationships with reciprocal and nonreciprocal intimate partner violence. Am J Public Health 2007;97:941-7

40 Ruiz-Pérez I, Plazaola-Castaño J, Vives-Cases C, et al. Methodological issues in the study of violence against women. $J$ Epidemiol Community Health 2007;61 Suppl 2:ii26-31.

41 Ellsberg $M$, Jansen HAFM, Heise L, et al. Intimate partner violence and women's physical and mental health in the WHO multi-country study on women's health and domestic violence: an observational study. Lancet 2008;371:1165-72.

42 Bonomi AE, Thompson RS, Anderson M, et al. Intimate partner violence and women's physical, mental, and social functioning. Am J Prev Med 2006;30:458-66.

43 Meekers D, Pallin SC, Hutchinson P, et al. Intimate partner violence and mental health in Bolivia. BMC Womens Health 2013;13:28-9.

44 Kapiga S, Harvey S, Muhammad AK, et al. Prevalence of intimate partner violence and abuse and associated factors among women enrolled into a cluster randomised trial in northwestern Tanzania. BMC Public Health 2017;17:190.

45 Aizpurua E, Copp J, Ricarte JJ, et al. Controlling behaviors and intimate partner violence among women in Spain: an examination of individual, partner, and relationship risk factors for physical and psychological abuse. J Interpers Violence 2017;886260517723744:0 88626051772374.

$46 \mathrm{Kim} \mathrm{J}$, Lee J. Prospective study on the reciprocal relationship between intimate partner violence and depression among women in Korea. Soc Sci Med 2013;99:42-8.

47 Fageeh WMK. Factors associated with domestic violence: a crosssectional survey among women in Jeddah, Saudi Arabia. BMJ Open 2014:4:e004242.

48 Feder G, Ramsay J, Dunne D, et al. How far does screening women for domestic (partner) violence in different health-care settings meet criteria for a screening programme? Systematic reviews of nine UK National Screening Committee criteria. 13, 2009. https://www.ncbi. nlm.nih.gov/books/NBK77121

49 Syed HR, Zachrisson HD, Dalgard OS, et al. Concordance between Hopkins symptom checklist (HSCL-10) and Pakistan anxiety and depression questionnaire (PADQ), in a rural self-motivated population in Pakistan. BMC Psychiatry 2008;8:59.

50 Sirpal MK, Haugen W, Sparle K, et al. Validation study of HSCL-10, HSCL-6, WHO-5 and 3-key questions in 14-16 year ethnic minority adolescents. BMC Fam Pract 2016;17:7. 